\title{
Agricultura e agronomia
}

\author{
ROBERTO RODRIGUES
}

$\mathrm{Q}$

UANDO olhamos para os últimos 80 anos da história brasileira, encontramos, na base do nosso progresso, um formidável avanço tecnológico na agronomia. Foi ela que abriu os horizontes de nossa agricultura e, a partir daí, criou o mercado para os produtos industriais e serviços da moderna economia.

Se não fosse a tecnologia agronômica, nossa poderosa indústria citrícola não existiria: os pomares teriam desaparecidos nos anos 40, destruídos pela "tristeza". Os canaviais teriam sido eliminados pelo carvão e pelo mosaico nos anos 50 . Os cafezais, nos anos 60, pela ferrugem. Não teríamos o milho híbrido nem o melhoramento do algodão. A soja não progrediria tanto com as novas variedades. Frutas, verduras e flores não teriam se desenvolvido da mesma forma.

Para onde quer que voltemos nossos olhos - grãos, raízes, fibras, frutas, legumes, pastagens, florestas - encontramos o testemunho formidável do trabalho dos engenheiros agrônomos, estes heróis que, somando sua luta à dos agricultores brasileiros, construíram o Brasil, hectare por hectare, semente por semente, décadas e décadas de anônima dedicação.

Só por isto, por seu esforço nas áreas de pesquisa, ensino, extensão, produção, deveriam ser respeitados, admirados e decantados pela sociedade urbanoindustrial de hoje. Mas não o são. Já foram, em passado recente, quando, nas cidades do interior, o agrônomo era tão importante quanto o juiz, o promotor, ou o presidente da Câmara Municipal. Por que isto mudou? O que mudou? Por que perderam valor perante os olhos dos cidadãos urbanos? E, mais ainda, o que fazer para resgatar esta verdade? Esta justiça?

Afinal, os agronegócios representam 21\% do PIB nacional, ou 25\% do total de produção do país. Empregam 37\% dos trabalhadores brasileiros e correspondem a $40 \%$ das nossas exportações, sendo o único grande setor superavitário da balança comercial. São, portanto, o maior negócio do país. E têm a maior importância social, pela geração de empregos.

No entanto, falta o proporcional peso na política: o agronegócio perdeu poder político, apesar de as lutas de alguns parlamentares que representam com dignidade o setor no Congresso Nacional. A agricultura perdeu poder político. Os agricultores perderam espaço, superados que foram por outros setores mais ágeis e melhor organizados. Daí a diminuição da importância social do agricultor e do técnico do setor. Eles são os condutores deste segmento politicamente de- 
cadente, apesar de a força social e econômica que detêm. Portanto, só a valorização do setor rural poderá catapultá-los para o espaço a que fazem jus, e ao qual têm pleno e legítimo direito.

Para encaminhar esta questão, é preciso compreender o que vem acontecendo: o dia em que caiu o Muro de Berlim representou uma data emblemática para a humanidade. É possível dizer que não houve um único cidadão do planeta que tenha escapado das conseqüências daquela efeméride. Longe da realidade está quem imagina que ali só se desvaneciam os sonhos utópicos do comunismo. Ou que estava proclamada a vitória do capitalismo. Longe, muito longe, disso.

Naquela data, dois veteranos conhecidos do homem se uniram em um matrimônio assustador: a globalização, velha senhora que vinha operando desde os vikings, com o liberalismo, ancião que já assombrara a Europa em outras eras. E esta veterana dupla pariu duas bestas apocalípticas que passaram a galopar sem bridão pelo mundo afora, destruindo esperanças, destroçando instituições e estruturas consolidadas e apeando governos das mais diversas colorações: a concentração de riqueza e a exclusão social, gêmeas e inseparáveis irmãs, que chegam ao início do terceiro milênio como a maior ameaça às democracias.

A agricultura brasileira não escapou da sanha de ambas, porque as conheceu juntamente com outras duas mudanças que ocorreram intramuros: a estabilização da moeda e a falência das políticas públicas para o campo, tudo no começo dos anos 90 .

Esta louca mudança de cenários em curto espaço de tempo (de um país fechado com alta inflação e governo intervencionista, para um país "arrombado" comercialmente, com inflação civilizada e Estado falido) levou o setor rural a sofrer uma perda de renda insuportável. No gráfico 1, preparado a partir de dados da Fundação Getúlio Vargas do Rio de Janeiro, é mostrado com clareza que entre 1980 e 2000, embora a área plantada no país não tenha crescido, os agricultores incorporaram tecnologia, aumentaram a produtividade por área e levaram a produção física a um incremento de $40 \%$. No entanto, o valor desta produção assim acrescida, caiu, no mesmo período, outros $40 \%$.

Isto explica porque, na transição de um cenário para o outro, os agricultores brasileiros se tornaram partícipes ativos de duas gigantescas revoluções: uma barulhenta e outra silenciosa. A revolução barulhenta está sendo executada pelos excluídos e pelos em via de ...

Recente trabalho do técnico do MA, Antonio Lício, demonstra que nos primeiros sete anos da década passada a agricultura desempregou cerca de dois milhões de pessoas, sem contar as centenas de milhares de pequenos produtores que perderam tudo o que tinham em função dos ajustes de índices dos planos Collor e Real, quando o descasamento entre dívidas e preços criou um fosso irreparável entre devedores e credores. Esta exclusão brutal bem que justifica o 
crescimento dos chamados movimentos sociais, como o MST. Não importa se tais movimentos se tornaram político-ideológicos, mas na sua origem, são consistentes. E os paliativos Securitização, Pesa, Recoop, Pronaf, Procera, entre outros, não resolvem a questão do endividamento, principalmente daqueles que entraram no Plano Real com créditos indexados pela famigerada TR. Esta revolução barulhenta só terminará com a solução definitiva dos problemas de endividamento ou com a "morte" econômica de seus atores.

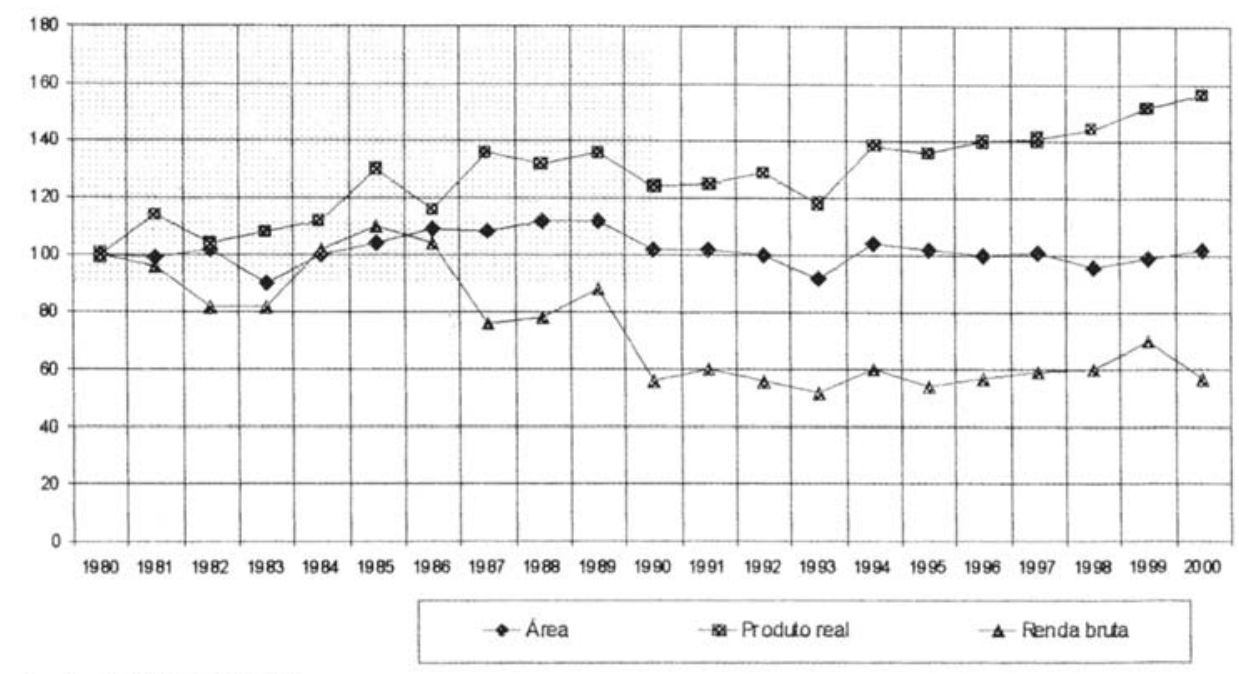

Fonte: FGV/IBRE/ CEA

Gráfico 1

Brasil - Indicadores de desempenho das lavouras - Índices $1980=100$

Por outro lado, há uma revolução silenciosa em andamento, servida pelos agricultores capitalizados, basicamente aqueles que não tinham dívidas no dia em que se implantou o Plano Real. Estes, no firme propósito de sobreviver, lá vão realizando um projeto fantástico, medido por três variáveis. A primeira é a inovação tecnológica, visível, decretada pela adoção das mais modernas máquinas, sejam tratores, colheitadeiras ou equipamentos, dotados de computadores de bordo, GPS e ar condicionado. Os insumos mais recentes são aplicados, assim como técnicas de ponta como o plantio direto e a agricultura de precisão. A segunda, menos visível, e certamente imensurável, é a revolução gerencial. Já não basta mais a melhor tecnologia, se o fazendeiro não for um bom gerente. É preciso ser bem informado para ser um comerciante ágil, para comprar insumos ou vender a produção na hora certa. Gerência financeira é indispensável, seja para tomar crédito com adequado mix de juros, seja para aplicar suas reservas. Saber calcular e pagar impostos já exige preparo, assim como cuidar das questões ligadas a custos de produção e organização do trabalho. Cuidados com a formação de recursos humanos e os contratos de trabalho são prioridades, bem como o adequado tratamento da questão ambiental, hoje fundamental inclusive em 
termos de comércio exterior. E a terceira vertente da revolução silenciosa é a mudança de modelo: trata-se da necessidade de agregar valor à produção primária. Já não é mais possível fazer renda compatível com os investimentos no campo vendendo grãos, por exemplo. É preciso transformá-los em óleo, farelo, carne ou leite. É preciso industrializar e distribuir tais produtos.

Naturalmente, isto exige uma radical transformação das cooperativas agropecuárias, que serão os principais agentes desta transformação. Também elas precisam profissionalizar-se, reduzir custos e melhorar seus serviços mediante fusões, incorporações, alianças estratégicas e bom marketing. Uma modernização dos contratos de parceria e de integração também serve à causa da agregação de valor. Torna-se essencial a adoção, na prática, do conceito teórico (já assimilado) de cadeia produtiva, de agribusiness. Mas mesmo estes agentes modernos da revolução silenciosa foram vítimas da tríplice colisão (globalidade, estabilização, Estado falido) e estão ameaçados em sua atividade.

Recente estudo dos brilhantes economistas Eliseu Alves, Mauro Lopes e Elisio Contini revela que, mantido o atual estado de coisas em termos da política econômica para o campo, dos atuais 4,9 milhões de produtores rurais restarão, em 15 anos, não mais que 600 mil. O número assusta, principalmente porque o sinal é muito claro quanto à exclusão do pequeno produtor rural. Assim, enquanto a sociedade gasta dinheiro para promover assentamentos, a economia nacional desassenta em muito maior escala, pressionando os centros urbanos por mais infra-estrutura, que também a sociedade tem de pagar.

A situação é tal que leva muitos representantes da classe rural a questionar sobre a validade de sua luta, e, mais ainda, sobre o futuro da agricultura no país, e até no mundo. Afinal, as tecnologias modernas aumentaram espetacularmente a produtividade; a ciência permite a produção de alimentos sintéticos que substituem os que a terra produz; segmentos como a engenharia genética e a hidroponia ocupam espaços crescentes. Chegará o dia em que a terra não precisará ser amanhada para produzir grãos, fibras e biomassa? Não parece possível.

Quem o afirma é Lester Brown, presidente do WorldWatch Institute que, por encomenda do governo japonês, realizou extensa investigação sobre o assunto concluindo que, nos próximos 20 anos, a produção agrícola crescerá menos que a população, elevando o patamar dos preços dos alimentos. Brown lastrea suas conclusões em três variáveis.

A primeira é a escassez de terras aráveis. Segundo ele, o mundo não tem muitas novas fronteiras agrícolas por conquistar, e as existentes ou têm baixa fertilidade ou estão muito longe dos centros de consumo, exigindo pesados investimentos em infra-estrutura. A segunda é a incapacidade de a ciência gerar tecnologias capazes de promover novos saltos espetaculares de produtividade por área. A terceira refere-se à diminuição da água disponível para irrigação, visto que a 
urbanização em todo o mundo, particularmente nos países asiáticos, exige mais água potável nas cidades para consumo humano.

Embora todos os argumentos de Brown sejam passíveis de discussão, é evidente - e ele mesmo o reconhece - que o Brasil constitui uma exceção: cultiva menos de um terço de sua área agricultável que, sendo em sua maioria cerrado, tem boas perspectivas de incorporar-se à área arada. É certo que nossa fronteira agrícola não dispõe de boa logística, mas as privatizações vão mudando esta realidade, além de termos quase um quinto da água doce do planeta. Assim, enquanto nossos agricultores vivem momentos de tensão que se eternizam desde a década desperdiçada dos 90, têm, aparentemente, um futuro alentador: com espaços amplos para uma poderosa agricultura orgânica, convivendo com a tradicional e até com os transgênicos, desde que absolutamente seguros. Há espaço para tudo neste país continente.

Como atravessar este atoleiro do presente para a glória de dois mil e qualquer coisa? Até o governo federal, há tantos anos dedicado a sucatear os instrumentos de política agrícola, se deu conta, recentemente, de que o agribusiness poderia resolver dois problemas que vão ficando crônicos. O primeiro, o da balança comercial, cujo saldo negativo nos últimos anos só não foi fatal porque os agronegócios foram superavitários, como sempre (gráfico 2). Isto se deve ao desempenho espetacular do setor, apesar de a falta de políticas adequadas (gráfi$\cos 3$ e 4). O segundo, o da geração de empregos. Está mais do que evidente que nenhum setor da economia gera mais empregos do que o agronegócio por cada milhão de reais investido. E se nesta conta entrarem setores específicos, como o de papel e celulose ou o de têxteis, a liderança dispara (gráfico 5). Com base nesta constatação, o presidente Fernando Henrique Cardoso criou, no segundo semestre de 1996, o Fórum Nacional da Agricultura, uma experiência inédita em que representantes do setor rural, do governo e do parlamento se debruçaram sobre os conhecidos diagnósticos dos problemas rurais e agroindustriais e, durante quase dois anos de dura faina, elaboraram um projeto formidável para $\mathrm{o}$ agribusiness, composto de dezenas de programas condensados em um documento chamado "As dez bandeiras do agronegócio". Cada uma delas era composta de diversos programas cujo encaminhamento estava dado.

Este histórico documento - porque contou com a participação desprendida de quase todas as entidades rurais (inclusive trabalhadores, pela Fetaesp) - foi entregue ao governo, com grande solenidade, em 2 de setembro de 1998.

Lamentavelmente, foi solenemente desprezado, talvez pela ignorância agrícola de nossas autoridades econômicas, embora algumas das propostas tenham caminhado em paralelo com os próprios trabalhos do FNA (caso da Lei Kandir, da Lei de Armazenagem e da Lei de Classificação dos Produtos Vegetais). Na prática, seu conteúdo poderia ser resumido em três grandes conjuntos de ações que, se empreendidas, fariam a ponte referida entre presente e futuro. 


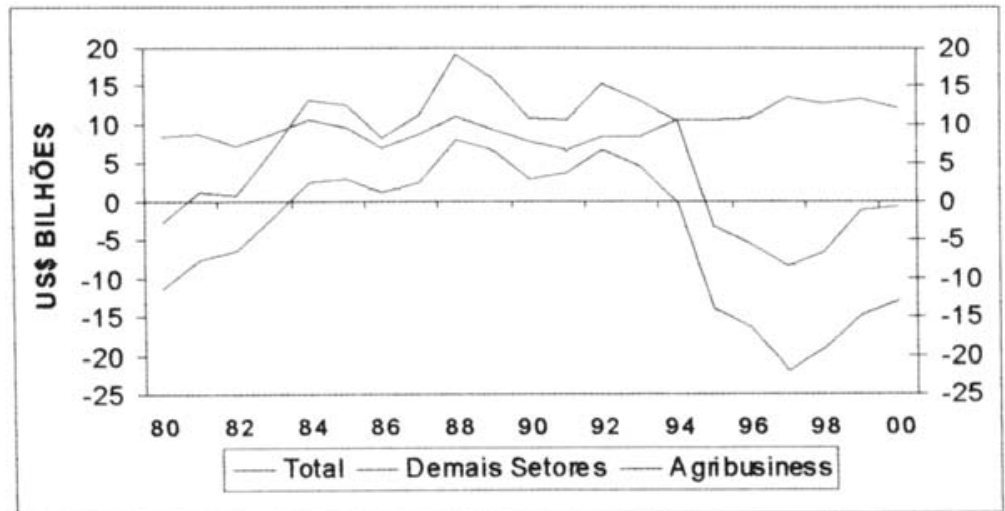

Fonte: Secex

Gráfico 2

Balança Comercial Brasileira

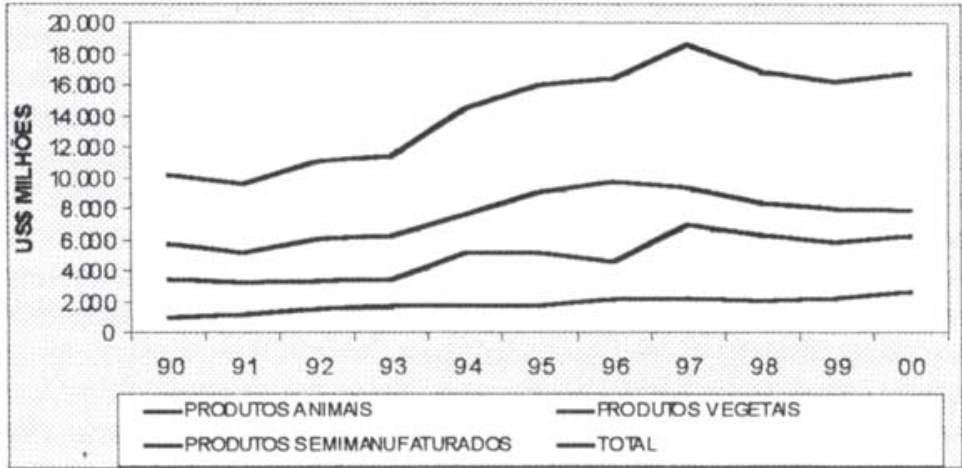

Outros: Gorduras, óleos, ceras, fumo, bebidas, suco de laranja, farelo de soja, açúcares, etc. Fonte: Secex

Gráfico 3

Exportações Agrícolas Brasileiras

O primeiro deles é definido pela reforma das políticas públicas, sob uma única referência: conferir igualdade de oportunidades para os produtores brasileiros, quando confrontados com seus colegas de países desenvolvidos. Nada se propõe ou se exige além de isonomia. Para tanto, é absolutamente essencial reformar as políticas macroeconômicas, especialmente a monetária (para atingir juros civilizados), a tributária (desonerar a produção) e a previdenciária, sem o que não se dará o ajuste fiscal, e até a reforma política. Depois virão as setoriais, em que tem peso uma política de renda mínima para o pequeno produtor. $\mathrm{O}$ seu êxodo para as cidades é decorrente de não obter renda na atividade. As intermináveis discussões sobre a necessidade de fixar o homem ao campo não consideram este aspecto, como se o agricultor fosse um eterno condenado a ficar fixo na roça, sem renda, porque assim o desejam os acadêmicos urbanóides do Brasil. 
Muito mais espertos do que parecem, os agricultores buscarão novas alternativas para educar seus filhos e cuidar da saúde de suas famílias se o campo não lhes der esta chance.

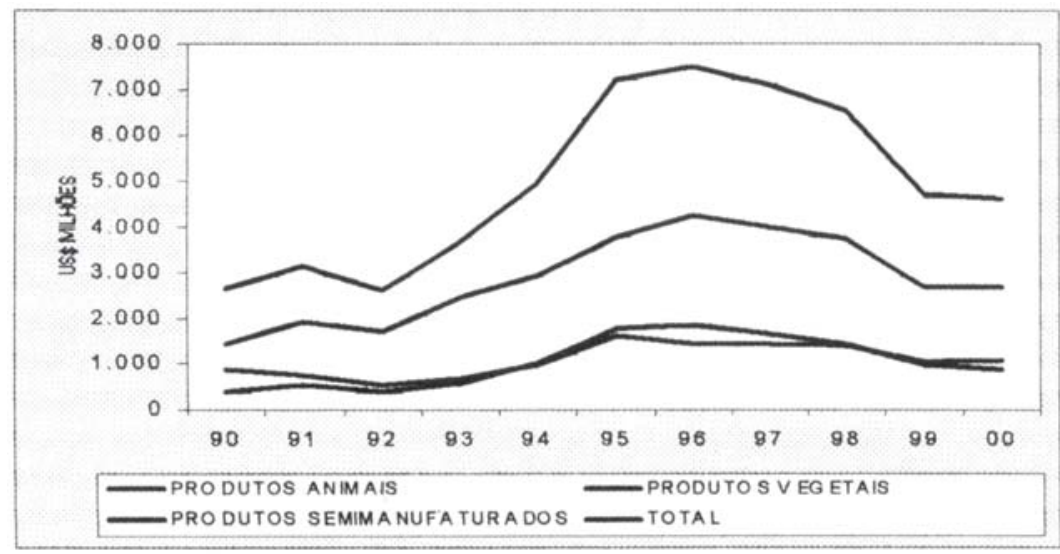

Outros: Gorduras, oleos, ceras, fumo, bebidas, suco de laranja, farelo de soja, açúcares, etc. Fonte: Secex

Gráfico 4

Importações Agrícolas Brasileiras

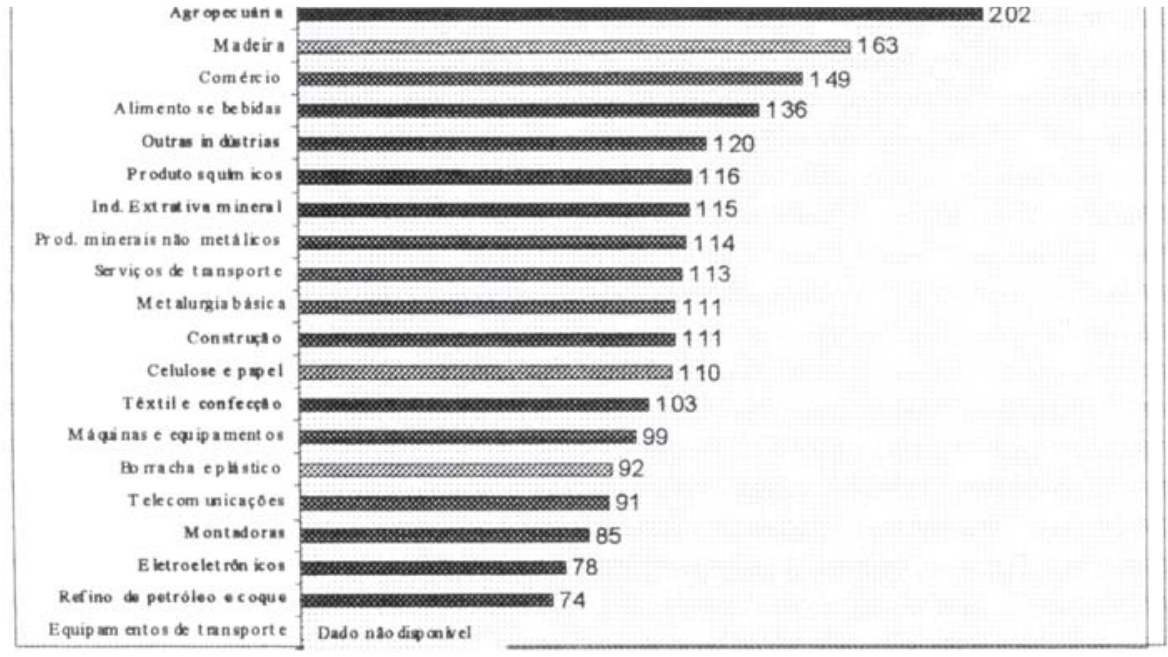

Fonte: BNDES(Folha de São Paulo, 26/09/99)

Gráfico 5

Empregos gerados (por R\$ milhão)

O segundo conjunto de ações relaciona-se à organização do setor privado, tanto política quanto econômica. Bolsas, cooperativas e agroindústrias devem participar desta reordenação institucional, sob a égide do agribusiness, promovendo inclusive uma reforma agrária sustentável. E, a partir daí, duas ações são fundamentais: cuidar da imagem do setor, tão vilipendiada pela contra-informa- 
ção, que a opinião pública acha que o agricultor ou é "barão" ou "jeca”, caloteiro ou incompetente, além de explorar menores e trabalhadores e destruir o ambiente. Adicionalmente, é preciso, de forma organizada, preparar o lobby sobre o legislativo e o executivo, buscando a reforma de quase 70 instrumentos legais, desde leis até regulamentos do BACEN, que entravam o desenvolvimento rural.

Finalmente, precisamos de boas negociações na área internacional, visando à conquista de mercados externos. Aqui está um ponto muito delicado. De nada adiantarão políticas públicas isonômicas com relação a nossos concorrentes, nem uma moderna organização privada com todo o marketing que ela possa fazer, se as regras de comércio exterior nos discriminarem. A oportunidade para esta virada é a rodada de negociação, organizada pela OMC, que deverá se estender por, no mínimo, três anos. Trata-se da obrigação assumida pelos países signatários do Acordo Agrícola extraído da Rodada Uruguai do GATT, que estabelece a plataforma básica para as novas negociações, a partir dos temas centrais: acesso a mercados, políticas de apoio interno e estímulos à exportação. Além destes temas, outros virão à tona nas novas negociações, como a cláusula social, a questão ambiental (alimentada pela tese da multifuncionalidade), os transgênicos entre outros. Na mesma onda estão aí as discussões sobre a ALCA e as relações entre Mercosul e União Européia.

O Brasil, que sempre se posicionou mal nestas negociações, seja pela desorganização do setor privado, seja pela desinformação do governo, tem agora uma nova postura. A ABAG, a CNA e a OCB organizaram-se em um Fórum Permanente de Negociações Agrícolas Internacionais, sediado em Brasília, que já definiu a posição brasileira quanto às questões gerais, bem como quanto às especificidades das diversas cadeias produtivas. O setor privado também está se articulando bem com o governo, especialmente com o Ministério da Agricultura e com o Itamaraty, que têm demonstrado boa vontade quanto ao entendimento. Mas é preciso uma sólida coordenação e ação de conjunto, porque a negociação dar-se-á sempre em bloco. Se um setor negociar em separado, poderá prejudicar a si mesmo ou a outros setores não enfocados naquele momento, até porque é visível um recrudescimento das práticas protecionistas, em função de duas circunstâncias: a exclusão social, já referida, que afeta duramente os produtores rurais dos países ricos. Estes, os ligados à OCDE, gastaram em 2000, cerca de US\$ 360 bilhões para proteger seus agricultores direta ou indiretamente, o que representa quase US\$ 1 bilhão por dia; enquanto isso, o Brasil fica no Pronaf e no Procera. Eliminar os subsídios e a proteção na Europa ou no Japão promoveria a falência de milhares de pequenos produtores, com conseqüências sociais que custariam mais caro que o atual modelo.

Além disto, é também evidente que a riqueza imensa dos países desenvolvidos lhes permite tais práticas protecionistas, significando que não existe apenas uma disputa por mercados entre agricultores de países ricos e pobres. Há, acima 
disto, uma disputa entre tesouros, o que nos coloca em situação bastante desvantajosa frente a norte-americanos, europeus e alguns asiáticos. Assim, é importantíssimo que nos organizemos ao máximo para evitar mais uma derrocada na OMC. Esta seria uma pá de cal na nossa já combalida economia rural.

Finalmente, cabe uma observação quanto a um ponto crucial: os efeitos da concentração sobre as cadeias produtivas no Brasil. Impulsionados pela competitividade, cresce o número de fusões no setor do agribusiness. Já é pequeno o número de fabricantes de tratores, devendo cair ainda mais. Também se reduz o número de produtores de sementes, defensivos e fertilizantes. Suas margens diminuíram e, premidos pelo ajuste cambial de janeiro de 1999, elevaram seus preços, sem que os produtos agrícolas acompanhassem estes aumentos. $\mathrm{Na}$ outra ponta, juntaram-se as indústrias de alimentos, de laticínios e esmagadores, assim como as empresas de distribuição e abastecimento. Pressionada pelos dois lados, a margem dos produtores vai também se reduzindo. Já se falou sobre isto, apontando-se o caminho da agregação de valor como a solução evidente.

Mas, fica nesta questão uma grande interrogação: qual será o grau de capacidade do Brasil de se livrar da dependência tecnológica? A concentração antes da porteira, somada ao diferencial de investimentos em tecnologia entre os países ricos e o nosso, está sinalizando um risco enorme de dependência.

Um dado esclarecedor a respeito é o volume de recursos destinados ao desenvolvimento tecnológico no Brasil e nos Estados Unidos. De acordo com o Ministério do Planejamento, em 1997, no Brasil, foram investidos em P\&D 1,15\% do PIB, equivalente a US\$ 8,76 bilhões, enquanto nos EUA, o valor foi bem maior, atingindo cerca de 2,5\%, correspondendo a US\$ 125 bilhões.

Eis aí um assunto que deve preocupar sobremaneira a Nação. Uma sociedade que não gera sua tecnologia, especialmente a agrícola, sendo a nossa tropical, bem diferente da dos países do hemisfério Norte, poderá ter futuro?

A tecnologia é a alavanca da competitividade. E aqui já se viu que os agricultores brasileiros souberam incorporar tecnologia, aumentar competitividade e abastecer a população do país, mesmo com sua renda caindo. Até quando será possível sustentar tal situação? Recentes estudos comandados pela Embrapa mostraram o impacto dos avanços tecnológicos no campo: um pedreiro da cidade de São Paulo teve uma redução anual de 5,25\% com seus gastos em alimentação nos últimos 25 anos! Até quando a concentração no agronegócio de países ricos estará excluindo nossos produtores?

Afinal de contas, nosso potencial produtivo é fantástico, como pode ser observado no quadro 1 .

Mas, na verdade, o desempenho das nossas exportações não tem sido tão espetacular quanto poderia, exatamente por falta dos três conjuntos de ações referidos. 
Tabela 1

Agibusiness no Brasil: Potencial produtivo

\begin{tabular}{|c|c|c|c|c|c|c|}
\hline & \multicolumn{3}{|c|}{ Atualmerte (2000) } & \multicolumn{3}{|c|}{ Potencial } \\
\hline & Produçâo & Área Colhich & Produtividade & Produçåo & Area Colhich & Produtividade \\
\hline & (milhoes t) & (milhøes ha) & (t/ha) & (milhoes $t$ ) & (milhoes ha) & (t/ha) \\
\hline Sqja & 36,0 & 13,7 & 2,6 & 80,5 & 23,0 & 3,5 \\
\hline Milho & 38,5 & 13,9 & 2,8 & 165,9 & 23,7 & 7,0 \\
\hline Arraz & 10,8 & 3,3 & 3,3 & 26,4 & 6,6 & 4,0 \\
\hline Algodbo (beneficiado) & 0,8 & 0,9 & 0.8 & 1,7 & 1,9 & 0,9 \\
\hline Cana-de-Aguicar & 250,0 & 4,8 & 52,1 & 443,3 & 4,9 & 90,0 \\
\hline Café (saca $60 \mathrm{~kg}$ & 31,1 & 2,0 & 15,6 & 45,0 & 3,0 & 15,0 \\
\hline Laranja (cx $40,8 \mathrm{~kg})$ & 438,0 & 0,9 & 486,7 & 867,0 & 1,0 & $\approx 7,0$ \\
\hline
\end{tabular}

Fonte: Agrianual, Pensa, MAA, CONAB, IBGE

\section{Conclusão}

Como, então, a tecnologia agrícola pode contribuir para uma agricultura sustentada, para um Projeto Brasil que nos leve para o Primeiro Mundo?

Até porque, pelo menos por enquanto, este é o veículo que temos, os agronegócios: falta algum tempo para vencermos também em outros setores nos quais é preciso investir mais em tecnologia. Embora o universo de trabalho a enfrentar nesta direção seja imenso, embora esteja tudo por fazer, é preciso definir prioridades para um projeto ser viável. Tentar abraçar todo o infinito levará à frustração e ao fracasso.

É essencial estabelecer a referência básica: uma agricultura sustentável é aquela inserida no mercado mundial de forma competitiva, com qualidade e preços, garantindo renda - e portanto estabilidade - aos agricultores, sob a ótica das cadeias produtivas, preservando os recursos naturais e cumprindo a função social da terra.

Sob tal conceito, talvez devessem ser estabelecidas três grandes prioridades:

- uma política interna que garanta renda aos agentes das cadeias produtivas;

- uma política externa que abra os mercados aos produtos brasileiros;

- uma política de formação de recursos humanos para o agronegócio brasileiro.

Para encaminhar as discussões sobre estes três assuntos, poderiam ser apresentadas algumas idéias gerais.

\section{Idéias para uma política de renda}

- Criação do Seguro Agrícola. É preciso privatizar o IRB.

- Criação do Programa Nacional da Correção e Conservação do Solo e Uso do Solo e da Água, com financiamentos de longo prazo. 
- Juros para o crédito rural compatíveis com os praticados no mercado internacional.

- Criação de instrumentos que garantam renda mínima ao pequeno produtor rural, com reconversão de atividades.

- Estímulo às bolsas de futuro via desoneração sobre o investidor estrangeiro e financiamento das margens através do crédito rural.

- Implantação de mecanismos de informações sobre estatísticas de mercado agrícola: estoques, localização, qualidade, custos etc.

- Isenção ou redução de tributos sobre a cesta básica e sobre os insumos agrícolas, máquinas e equipamentos.

- Eliminação de impostos em cascata (PIS, Cofins etc.) via comercialização interna e externa de produtos agrícolas, bem como eliminação do IOF em Bolsas para operações de mercado agrícola.

- Eliminação do ITR sobre áreas de preservação ambiental e florestas.

- Instituição da cobrança do ICMS (enquanto existir), no destino.

- Criação de um instrumento legal para ações de C\&T na linha dos "Institutos de Pesquisa", apoiado pelo Projeto de Lei n. ${ }^{\circ} 2950$, de 1997, que:

- concilie a estabilidade politica-institucional da pesquisa pública com a necessária flexibilidade administrativo gerencial;

- utilize mecanismos que estimulem a competitividade, eficiência e avaliação de resultado;

- incentive a parceria dos setores público e privado.

- Criação de mecanismos e aperfeiçoamento dos existentes, de modo a:

- aumentar seletivamente as dotações para a pesquisa, principalmente através de fundos;

- aumentar a participação do setor privado através de fundos de caráter privado e incentivos governamentais;

- simplificar a legislação de incentivos (Lei 8.661) e facilitar o acesso do setor privado aos recursos oficiais da Finep, CNPq, BNDES.

- Restruturação dos serviços estaduais de assistência técnica e extensão rural, com a participação do governo federal e da iniciativa privada, para apoiar prioritariamente pequenos produtores, em regime de agricultura familiar, sob a ótica do desenvolvimento rural sustentável, bem como a implementação de programas de capacitação com o uso intensivo dos instrumentos modernos da tecnologia da informação.

- Criação de um programa nacional de incentivo ao manejo integrado de pragas, doenças e plantas invasoras (MIP), com a realização de pesquisas e treinamento para agricultores e extensionistas. 
- Criação de mecanismos que incentivem o crescimento da agricultura orgânica, com certificação e rastreabilidade.

- Criação de mecanismos que permitam a utilização do condomínio e de áreas comuns, entre produtores, para o cumprimento de exigências legais.

- Privilégios para a execução de políticas públicas para a agricultura familiar por meio de cooperativas ou associações, implementando inclusive subvenções de caráter econômico-social.

- Estímulo a um maior relacionamento e integração dos agricultores organizados com as agroindústrias, incentivando projetos de beneficiamento e/ ou transformação de produtos por parte de grupos de pequenos produtores (agricultura familiar).

- Dotação às comunidades de infra-estrutura sócio-econômica, que facilitem a execução de projetos de investimentos produtivos, geração de renda e emprego, com a participação do poder público e de organizações privadas, constituídas por grupos de pequenos produtores.

- Firme garantia do Poder Executivo quanto ao direito constitucional à propriedade privada, reprimindo os abusos contra a lei, como invasões a propriedades.

- Fortalecimento e ampliação do alcance do Banco da Terra, com a alocação de recursos orçamentários para aquisição de terras por arrendatários, jovens agricultores, assalariados rurais e pequenos agricultores, inclusive por intermédio de associações e cooperativas.

- Incentivo à implantação de projetos privados de assentamento, por cooperativas ou empresas colonizadoras, visando reduzir a tensão no meio rural.

- Criação de mecanismos legais e de ampliação de crédito fundiário, para que proprietários de terras ociosas se incorporem em programa de loteamentos de glebas rurais, a serem disponibilizadas para agricultores sem terra.

\section{Idéias para uma política de comércio exterior}

- Criação do Comitê Permanente de Negociações Internacionais, composto por representantes de governo, setor privado, academia e parlamento, presidido pelo ministro da Agricultura, com o fim de assessorar o Itamaraty em negociações internacionais, no âmbito dos agronegócios, na OMC, na ALCA, no Mercosul, entre outros organismos das relações comerciais.

- Formação de negociadores para os agronegócios, que constituirão futuros adidos agrícolas em embaixadas selecionadas.

- Regulamentação e implementação de legislação que permita a aplicação de capital de risco para o financiamento de empresas de base tecnológica.

- Reorientação institucional da Secretaria de Defesa Agropecuária e das secretarias estaduais e municipais de Agricultura, com a organização e mon- 
tagem de uma autarquia que tenha personalidade jurídica, autonomia administrativa e financeira, permitindo parcerias com a iniciativa privada.

- Implantação de um programa de qualidade e sanidade, centrado nas cadeias produtivas do agronegócio e engajamento das instituições públicas e privadas de pesquisa na descrição e certificação de conformidade de processos produtivos e criação de centros de referência de qualidade.

- Estímulo à criação de instituições nacionais que organizem a rastreabilidade e certificação de produtos agrícolas e dos agronegócios.

- Incentivo ao manejo sustentado de recursos naturais e seu monitoramento, desburocratizando as atividades, eliminando exigências excessivas de licenças, estabelecendo sistemas padrão simplificado, mediante legislação adequada.

- Desenvolvimento de estratégias nacionais, programas e planos para ampliar a base genética das principais culturas e conservação de microorganismos de interesse para a agricultura, estimulando a criação e o manejo de parques nacionais com vistas à preservação da biodiversidade.

- Incentivos à difusão de sistemas alternativos de produção, tais como a agricultura orgânica, biológica, polinização dirigida e outros, e de tecnologias preservacionistas como plantio direto, uso racional dos recursos hídricos, rotação de culturas, conservação do solo etc.

- Revisão da legislação trabalhista rural, visando à sua modernização e adequação à nova realidade no país, melhorando as relações laboral e patronal, propiciando assim a elevação no nível de emprego.

- Ampliação de sistemas intermodais de transportes, especialmente a hidrovia e a ferrovia visando a baratear o custo do frete de produtos e insumos.

- Criação da Agência de Desenvolvimento do Agronegócio.

Nas negociações, seja na ALCA ou na OMC, seja nas relações entre a UE e o Mercosul, uma posição deve estar clara: o Brasil tem um mercado consumidor que é a grande atração para todo os países desenvolvidos. Este é o nosso cacife e precisamos usá-lo bem no difícil jogo dos mercados. É um cacife de valor, e nossa posição negocial deve ser nele calcada.

Por outro lado, se os países desenvolvidos mencionam a proteção de seus produtores por questões sociais, devemos usar o mesmo discurso, porque sabemos que a falta de renda no campo causa exclusão social: temos o exemplo disto aqui mesmo.

Assim, o discurso é claro: a agricultura é multifuncional na Europa, mas é também aqui. Vamos usar os argumentos dos ricos para vencê-los.

Podem proteger o quanto quiserem, desde que isto não represente a formação de excedentes exportáveis para terceiros países, onde não podemos con- 
correr. O argumento é sólido, porque desmascara quem estiver usando o discurso social com outros objetivos e se enquadra na chamada Caixa Verde dos Acessos a Mercados.

Finalmente, é fundamental uma boa articulação entre setor público, setor privado e academia na formulação e sustentação da nossa política comercial. A criação de um Comitê de Negociações Agrícolas Internacionais com tal composição, presidida pelo ministro da Agricultura e com um braço no Congresso Nacional seria um excelente instrumento. Acabaria com a "Solidão do Negociador" e daria agilidade às posições brasileiras.

\section{Idéias para uma política de RH para o agronegócio}

Os profissionais de ciências agrárias, em especial o agrônomo, têm condições de atuar em todos os pontos aqui referidos, começando em todos os níveis da área tecnológica.

Nos itens referentes à revolução silenciosa, principalmente, têm um papel relevante, e também na organização dos produtores, seja em cooperativas ou associações, seja em alianças estratégicas.

E, não apenas nesses aspectos, mas nas idéias sobre política de renda e de negociação internacional, o agrônomo tem tudo a ver: na solução do endividamento, na revisão fundiária, na questão ambiental, no seguro rural, no crédito, enfim, não há tema no qual ele não deva estar, com papel de destaque. Também no marketing e na agregação de valor.

É para isto que nossas Universidades devem olhar. Não basta a tecnologia, embora sem ela todo o resto seja inútil.

$\mathrm{O}$ agrônomo precisa ser um cidadão integrado à realidade do seu país, comprometido com sua história e com sua geo-economia. A agricultura não é um setor à margem da economia, mas a verdadeira base dos outros setores. E o engenheiro agrônomo é o agente deste processo; é ele o motor que faz girar a roda da economia, cujo eixo é o agricultor, pequeno, médio ou grande.

Se nos decidirmos pelas mudanças necessárias, então, não haverá dúvida. Os profissionais do setor serão reconhecidos como o motor referido e o Brasil, finalmente, com uma agricultura verticalizada, sustentável e competitiva, levará este país à Constelação dos Países Desenvolvidos, justos, democráticos. Daremos Paz a esta Nação, pela qual vale a pena viver. Pelo qual vale a pena morrer.

Roberto Rodrigues, engenheiro agrônomo e agricultor, é presidente da Aliança Cooperativa Internacional e da Associação Brasileira de Agribusiness e professor de Economia Rural na Unesp-Jaboticabal. 